Validation of learning progression in scientific imagination using data from Taiwanese and Finnish elementary school students

\title{
Wang, Chia-Chi
}

2017

Wang , C-C , Niemi , H , Cheng , C-L \& Cheng , Y-Y 2017 , ' Validation of learning progression in scientific imagination using data from Taiwanese and Finnish elementary school students ' , Thinking Skills and Creativity , vol. 24 , pp. 73-85 . https://doi.org/10.1016/j.tsc.2017.02.014

http://hdl.handle.net/10138/310587

https://doi.org/10.1016/j.tsc.2017.02.014

cc_by_nc_nd

acceptedVersion

Downloaded from Helda, University of Helsinki institutional repository.

This is an electronic reprint of the original article.

This reprint may differ from the original in pagination and typographic detail.

Please cite the original version. 


\title{
Validation of learning progression in scientific imagination using data from Taiwanese and Finnish elementary school students
}

\begin{abstract}
This study validated learning progression in scientific imagination and compared the performance of Taiwanese and Finnish elementary school students on scientific imagination tasks. A total of $1505^{\text {th }}$ and $6^{\text {th }}$ graders completed the Scientific Imagination Test-Verbal (SIT-Verbal). Multiple analyses related to the validity of the SIT-Verbal were conducted using the Rasch partial credit model. Differences in scientific imagination due to gender and country of residence were assessed using $t$-tests. The results indicated that the various components of scientific imagination were hierarchically ordered, except for conceptualisation/organisation/formation. No differences in scientific imagination due to gender or country of residence were observed. Suggestions for future research are offered.
\end{abstract}

Keywords: scientific imagination, processes, learning progression, Scientific Imagination Test-Verbal, Taiwan, Finland 


\section{Introduction}

Back to the Future Part II is an American science-fiction adventure comedy film from 1989. The vision of the future portrayed in the film enthralled audiences when it was first released, and over 25 years later, its version of the future has proven to be more accurate than might have been expected. Whilst hover boards, self-lacing shoes, and virtual-reality headsets did not exist in the 1980s, some of the technology depicted in the film has now become a reality (http://www.techinsider.io/things-back-to-the-future-2-got-right-2015-10). Through the use of their imagination, people can develop their creative ideas to become real products or objects based on those ideas (Eckhoff \& Urbach, 2008). Imagination drives people to explore the world, pursue their interests, solve problems, and develop new abilities that are needed for the future (Church, 2006). In other words, imagination affects our thinking, language, and experiences on a daily basis (Adams, 2004; Grant, 2004; Mountain, 2007; Wang, Ho, \& Cheng, 2015a, b).

In recent years, many countries around the world have increased their efforts to promote and support imagination-related research. Key examples include projects such as "Imagining the Future", a course created by the Writing and Humanistic Studies Department of the Massachusetts Institute of Technology (MIT) and the Imagination Institute, established by the Positive Psychology Center at the University of Pennsylvania (http://imagination-institute.org/) in the United States, as well as the Imaginative Education Research Group, established by Simon Fraser University in Canada (http://ierg.ca/). Among the countries engaging with this field, Finland has performed outstandingly in promoting education targeted at innovation, creativity, and imagination. In the 2014-2015 Global Competitiveness Report of the World Economic Forum, Finland was ranked top of 144 economies on both the Innovation and the Higher Education and Training indices. Finland is an example of a nation that has transformed itself from a remote agrarian/industrial state in the 1950 s to a model knowledge economy state, using education as the key to economic and 
national development. Finnish education policies are designed to increase student achievement and national competitiveness (Sahlberg, 2007). The success of these policies is reflected in the outstanding performances by Finnish students on international assessments (e.g., the Program for International Student Assessment: PISA) (Reinikainen, 2012, p. 3-18; Sahlberg, 2007). Finnish students are not subjected to routine testing, and schools are granted considerable pedagogical freedom (Niemi, Multisilta, Lipponen, \& Vivitsou, 2014). The combination of using imagination and life experiences has become an important educational paradigm in the Finnish system. Besides, Finnish educational initiatives, such as the 2012 Hernesaari Local Masterplan (Lin, 2011; Meskanen, 2012), serve as good models for the integration of imagination, creativity, and innovation.

Similarly, in recent decades, Taiwan has placed increasing emphasis on technological innovation, creativity, and scientific imagination. Beginning in 2009, the Ministry of Science and Technology (MOST) and the Ministry of Education (MOE) have promoted education and research related to imagination by recruiting people to participate in projects focusing on imagination and technology research and on nurturing practical skills (Department of Science Education, 2009), thereby substantially increasing the country's capacity for generating research related to technological development. The MOE Advisory Office designated 2011-2014 as a period for establishing "a program for the future of imagination and creativity in education", with the main theme of "nurturing individuals with imagination for the future, for caring, and for practical applications" (MOE Advisory Office, 2012). Although education authorities in Taiwan aim to advocate scientific imagination and creativity, the volume of memorisation and repetition tasks, which remain typical educational methods used in many Asian countries, has been a major impediment (Kim, 2005; Wu, 2002). Previous experience at an educational site in Taiwan showed that creativity and imagination in Taiwanese students may be limited or stifled by an exam-oriented culture that requires a single correct answer (Wu, 2002). This exam-oriented culture restricts not only teachers' 
instructional practices but also the development of creativity and imagination among students. Creation and invention originate from a rich imagination (Ho, Wang, \& Cheng, 2013). Using Finland as a positive role model for Taiwan to progress economically and in innovation, it is of value to explore how Finnish students think and to be able to measure their imagination for use as a reference for Taiwanese imaginative education.

\section{Literature review}

Scientific imagination and creativity

Many scientific theories and inventions have come from ideas that originated from the human imagination (Wang et al., 2015a). Scientific imagination is one aspect of scientific creativity, which plays an important role in the development of science theory (Hu \& Adey, 2002; Lin, Hu, Adey, \& Shen, 2003). Scientific creativity is an intellectual trait, or the ability or potential to produce a certain product that is original and has a social or personal value, designed with a certain purpose in mind, using some given information. It covers creative science experiments, creative scientific problem finding and solving, and creative scientific activity, which all require scientific knowledge and skills (Hu \& Adey, 2002). Scientific imagination is a mental activity involving the creation of new ideas that are consistent with scientific principles and linked to daily life experiences (Ho et al., 2013); it is an intellectual trait with the ability to produce, or potentially produce, a product. It can be inferred that scientific imagination plays a significant role in scientific creativity. Although there is an increasing body of research focusing on scientific creativity, very few studies (e.g., Cruz \& Smedt, 2010) have dealt with scientific imagination, and this prompted our exploration of the constructs of scientific imagination and learning progression (LP) of scientific imagination.

\section{The definition and components of scientific imagination}

Ho et al. (2013) proposed the notion of scientific imagination as a type of purposeful 
imagination applied to a scientific discipline. They defined scientific imagination as a form of mental activity involving the creation of new ideas consistent with scientific principles and that are linked to daily life experiences. By studying award-winning teachers and students participating in the International Exhibition for Young Inventors (IEYI) competition, they argued that the process of scientific imagination consisted of three key stages, namely, initiation, dynamic adjustment, and virtual implementation, and four underlying components, namely, brainstorming (Man-hsiang，漫想), association (Lien-hsiang，聯想),

transformation/elaboration (Chi-hsiang，奇想), and conceptualisation/organisation/formation (Miao-hsiang，妙想). Here, multiple life experiences (e.g., reading science fiction novels, watching movies, playing, attending seminars, and travelling) were considered as the most influential factors in the scientific imagination processes. The daily life experiences of students are not only a source for developing new ideas but also act as a guide to help students to identify relationships between different ideas (Wang, Ho, Wu, \& Cheng, 2014). Ho et al. (2013) used the example of the "Illuminated Shoes" that contain a flashlight, and which were created by a group of Taiwanese elementary school students. Their invention was motivated by their past experience of trying to find their way in the dark. Ho et al. (2013) described the entire process experienced by the students of the use of their scientific imagination, including where they encountered the different scientific principles and functions (e.g., LED light placement and the circuit diagram of the power supply).

\section{The learning progression of scientific imagination}

In recent years, LP has been regarded as a more sophisticated method to analyse a particular topic over an extended period of time and can be used as a template for the development of curriculum and assessments. LP has been used to explore "the big ideas" in scientific disciplines, for example, scientific modelling and scientific argumentation in 
science education (Wang et al., 2015a). Under this premise, Wang et al. (2015a) identified an LP for scientific imagination based on a measured approach using the Berkeley Evaluation and Assessment Research (BEAR) Assessment System (BAS; Wilson, 2005, 2009). The aim was to obtain a better understanding of the core ideas and developmental trajectory of the process of scientific imagination and to align curricular development, instruction, and assessment through the construction of LP. It is noteworthy that the LP for scientific imagination in their study was focused on $5^{\text {th }}$ and $6^{\text {th }}$ grade elementary school levels. Finally, Wang et al. (2015b) revised the contents of the LP (Table 1) and the scoring guidelines for assessing scientific imagination based on their previous research.

Table 1 Learning progression for scientific imagination and its indicators

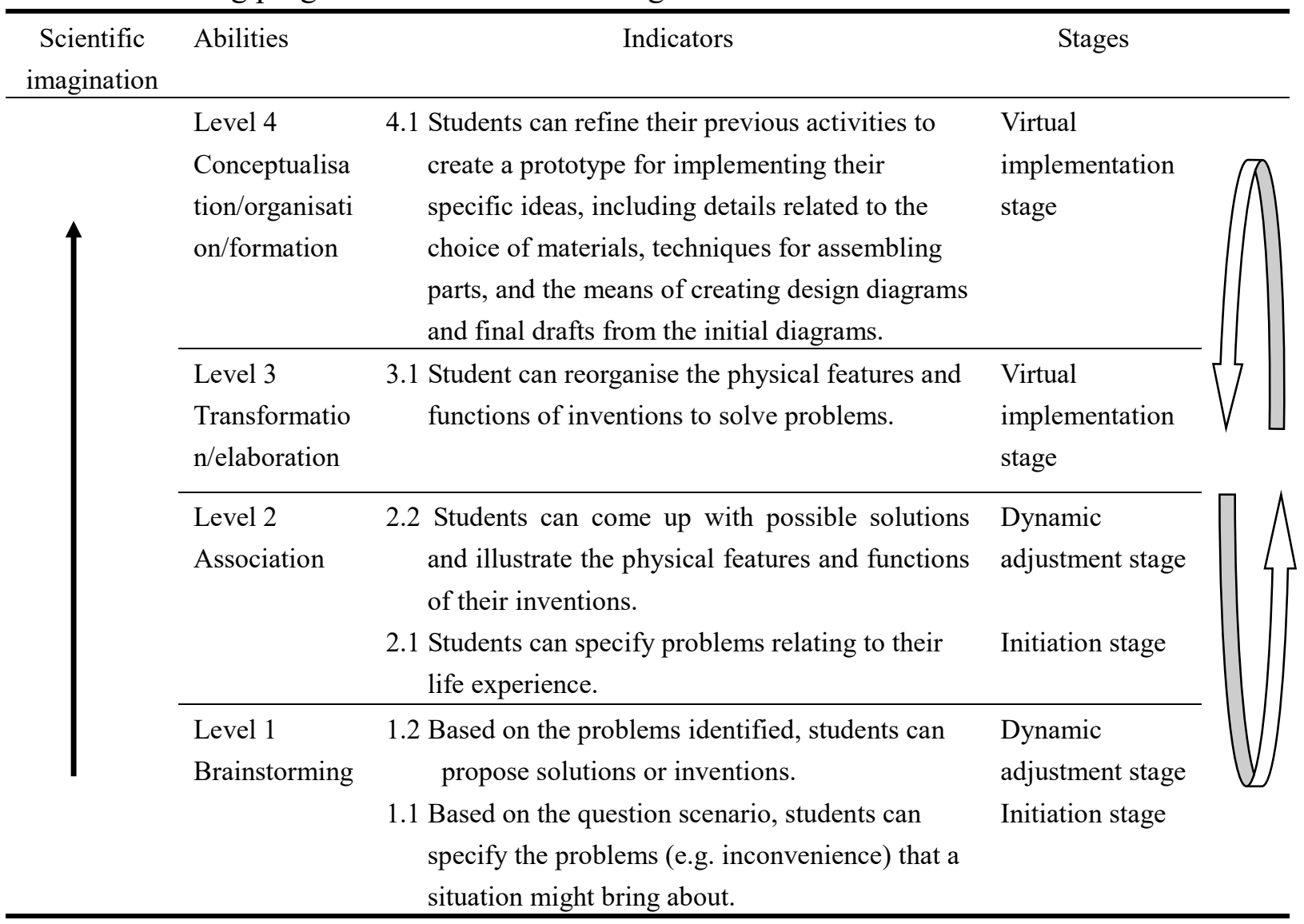

Note. From "Validation of the Scientific Imagination Test-Verbal", by C. C. Wang, H. C. Ho, \& Y. Y. Cheng. 2015, Paper presented at the Pacific Rim Objective Measurement Symposium (PROMS) 2015, Fukuoka, Japan. 
Based on their revised LP related to scientific imagination (Wang et al., 2015a), the scoring guidelines for the Scientific Imagination Test-Verbal (SIT-Verbal) were revised to measure scientific imagination in $3^{\text {rd }}$ to $6^{\text {th }}$ grade elementary school students. The SIT-Verbal was deemed suitable for measuring students' scientific imagination at the elementary school level, although differences in daily life experiences and stages of cognitive development should be considered in assessing scientific imagination in these cases. However, the development of suitable LPs is an iterative process that requires ongoing research. Wang et al. (2015a) also suggested that LP for scientific imagination may differ depending on age, gender, or background. To provide additional empirical evidence (e.g. cross-sample and cross-gender) on the validity of LP in scientific imagination (Wang et al., 2015a, b), we aimed to validate LP in scientific imagination using samples from Taiwanese and Finnish elementary students. The results may serve as a valuable reference pertaining to Asian (Taiwanese) and Western (Finland) cultures, providing useful information for future science education initiatives aimed at cultivating scientific imagination.

\section{Method}

\section{Participants}

This study aimed to validate LP in scientific imagination (Wang et al., 2015a, b) using data from Taiwanese and Finnish elementary school students. Data were collected from students in both countries, by means of purposive sampling.

Taiwanese students. A total of $745^{\text {th }}$ and $6^{\text {th }}$ graders from elementary schools in southern Taiwan were recruited; of these, $2.70 \%$ were $5^{\text {th }}$ graders $(n=2)$ and $97.30 \%$ were $6^{\text {th }}$ graders $(n=72) ; 54.10 \%$ of the participants were male $(n=40)$ and $45.90 \%$ were female $(n=34)$. The Taiwanese students were aged between 11 and 13 years $(M=11.99$ years; $S D=0.59)$. Finnish students. A total of $765^{\text {th }}$ and $6^{\text {th }}$ graders from comprehensive schools in 
Helsinki were recruited; of these, $23.70 \%$ were $5^{\text {th }}$ graders $(n=18)$ and $76.30 \%$ were $6^{\text {th }}$ graders $(n=58) ; 46.10 \%$ of the participants were male $(n=35)$ and $53.90 \%$ were female $(n=$ 41). The Finnish students were aged between 10 and 13 years $(M=11.82$ years; $S D=0.69)$.

\section{Instrument}

The SIT-Verbal, designed by Wang et al. (2015a), is a situation test that measures $5^{\text {th }}$ and $6^{\text {th }}$ grade elementary school students' scientific imagination, and is composed of four components, comprising brainstorming (Man-hsiang，漫想), association (Lien-hsiang，聯想),

transformation/elaboration (Chi-hsiang，奇想), and conceptualisation/organisation/formation (Miao-hsiang，妙想). A small revision was made to the methods regarding the items and scoring guidelines. A bilingual (Chinese/Finnish) version of the SIT-Verbal was drafted to measure Taiwanese and Finnish students' scientific imagination. The back-translation of the SIT-Verbal (Wang et al., 2015b) was carried out by two bilingual experts who translated the English version of the questionnaire into Finnish, and one expert who verified the consistency between these two versions.

The test introduced the pupils to a situation involving a space mission to another planet in which they encountered "a lot of falling leaves" at a school on the planet. In the open-ended test, students were required to complete two missions (Table 2). The first mission (Mission 1) consisted of three questions. The first question addressed brainstorming (Man-hsiang, 漫想) and required the participants to identify potential problems posed by the situation of "a lot of falling leaves" at the school. Based on Question 1, the second question (Question 2) addressed association (Lien-hsiang, 聯想) and asked the students to assess how these problems might influence their daily lives. The third question (Question 3) addressed both brainstorming and association, and tasked the students with designing solutions to the 
problem.

Following the successful completion of the first mission (answering the first three questions), the students were given a second mission (Mission 2), in which they had to draw one "new invention" to solve the problem identified in Mission 1. The transformation/elaboration (Chi-hsiang，奇想) and conceptualisation/organisation/formation (Miao-hsiang，妙想) components were assessed in Mission 2. The test covered six items related to the four components. The time given to the students to complete both missions was limited to 15 minutes.

The scoring guidelines for student responses were developed through expert consensus based on three meetings/discussions and on pre-test results (Wang et al., 2015a, b). The test administrator/rater (and the first author of this study) evaluated the responses. To overcome potential rater inconsistency arising from cultural differences, the same test administrator/test rater, who also co-developed the SIT-Verbal in Taiwan, went to Finland to collect the data from the Finnish students and rated their responses.

The quality of the students' responses was ranked from "category 0" (the lowest level) to "category 3" (the highest level). See Appendix A for the scoring guidelines.

Table 2.

Content included in the revised version of the Scientific Imagination Test-Verbal (SIT-Verbal).

\section{Mission 1}

The planet LABIDO has rich natural resources and minerals that could help to solve crises facing the earth. However, LABIDO is in big trouble now. You have been chosen as one of the spacemen to undertake an adventure to help LABIDO. Before your journey, you need to accomplish one mission. Then you can go to LABIDO and complete the second mission with the other spacemen.

Situation:

"There is a school on LABIDO. Many trees are planted at the school. There are always lots of falling leaves near the trees...." Please answer the following questions.

1) Question 1: What problems might this situation bring about? (The more problems you can think of the better)

2) Question 2: Based on Question 1, how might these problems influence daily life? ( The more 
influences you can think of the better )

3) Question 3: How many solutions can you think of? (The more solutions the better )

\section{Mission 2}

Based on the same situation, please draw one "new invention" that you think can efficiently solve the problem described in the situation. You have to explain the materials you will need for your new invention and specify the functions of this invention. Please also give your invention a name. Time limit for these two missions: 15 minutes.

Analysis

In this study, the data were analysed in two phases: process validation and analysis of differences. First, the Rasch partial credit model (Rasch PCM; Masters, 1982) was used to conduct process validation for the Taiwanese and Finnish data. This model consists of two primary parameters: the person's $(n)$ ability $\left(\theta_{n}\right)$ and the difficulty $\left(\delta_{i}\right)$ of the item $(i)$. When person $n$ responds to item $i$, the probability that this person will provide the correct answer for this item is as follows:

$$
P_{n i x}=\frac{\exp \sum_{j=0}^{x}\left[\theta_{n}-\left(\delta_{i}+\tau_{i j}\right)\right]}{\sum_{k}^{m_{i}} \exp \sum_{j=0}^{k}\left[\theta_{n}-\left(\delta_{i}+\tau_{i j}\right)\right]}, x=0,1, \ldots, m_{i},
$$

where $P_{n i x}$ is the probability of person $n$ scoring $x$ on item $i$. Additionally, $\theta_{n}$ (scientific imagination ability), the latent trait level of person $n$, is the target of the measurement, and $\delta_{j}$ is the overall difficulty of item $i$ (e.g., difficulty or threshold value). To compare the hierarchies related to scientific imagination, we calculated the Thurstone thresholds for each item. Because the revised version of the SIT-Verbal uses a four-point scale, each item has three Thurstone threshold values. The $k$ th Thurstone threshold of each item on the SIT-Verbal corresponds to the threshold point at which the probability of the participant obtaining a score below $k$ is equal to the probability of that participant obtaining a score equal to or higher than $k$ (Linacre, 1998). Taking indicator 1.1 as an example, the lowest performance (Level 0) for student brainstorming in the initiation stage is, "students cannot suggest what problems (e.g., inconvenience) the situation might bring about"; the highest performance (Level 3) is, "students can specify at least three problems the situation might bring about." This study 
focused on responses at or above "Level 2," which is the lowest cut-off point for classifying a student with more/less scientific imagination (Level 2) where, "students can specify two problems that the situation might bring about" (Wang et al., 2015a, b). Therefore, we used the second Thurstone threshold for each item as a reference point to compare differences in scientific imagination. Parameters of the Rasch PCM were estimated using the ConQuest computer program (Wu, Adams, \& Wilson, 2007).

For process validation, we assessed the content validity, structural validity, generalisability, substantive validity, and interpretability (Messick, 1994, 1995a, b; Wolfe \& Smith, 2007) of the SIT-Verbal using Rasch PCM analysis. For content validity, we presented which and how the items and the score guidelines of the SIT-Verbal were revised. Regarding structural validity, the Rasch PCM was used to examine the fit of each item and the unidimensionality of scientific imagination. When the data fit the expectations generated by the model, the expected value of the infit and outfit mean-square (MNSQ) is unity. An MNSQ value between 0.6 and 1.4 was set as the criterion for a reasonably good model-data fit (Bond \& Fox, 2007). With regard to substantive validity, the current hypothesised scores for each item represented different levels of student understanding. In principle, the hypothesised item hierarchy should match the empirically derived hierarchy. In addition, for each item, we also provided the percentage of times each category was chosen. Regarding generalisability, differential item functioning (DIF) analyses were conducted across genders and countries. Furthermore, person separation reliabilities (Schumacker \& Smith, 2007) were calculated to determine measurement precision. As Wright Maps are graphical and empirical representations of construct maps showing how a construct unfolds or evolves with increasingly sophisticated student performance, they were used in this study to represent simultaneously the participants' scientific imagination level and the difficulty of items; this allowed for hierarchies related to scientific imagination to be evaluated for each item.

Finally, we assessed both the Taiwanese and the Finnish data for differences in scientific 
imagination due to gender using $t$-tests and evaluated any differences in scientific imagination between the two countries.

\section{Results}

Multiple validities of the scientific imagination process in Taiwanese and Finnish samples

Content and structural evidence. The Rasch PCM was used to examine the

unidimensionality of scientific imagination. The results based on the Taiwanese and Finnish data revealed that most of the items had acceptable infit and outfit MNSQs in the second step (range: $0.6-1.4$ ), except for item 4.1 for the Taiwanese students (Table 3 ).

Generalisability evidence. DIF analyses were conducted for scientific imagination. All of the estimates of the differences in item difficulty by gender in the Taiwanese $\left(\triangle \mathrm{DIF}_{1.1}=0.18\right.$;

$\left.\triangle \mathrm{DIF}_{1.2}=0.04 ; \triangle \mathrm{DIF}_{2.1}=0.36 ; \triangle \mathrm{DIF}_{2.2}=0.49 ; \triangle \mathrm{DIF}_{3.1}=0.41 ; \triangle \mathrm{DIF}_{4.1}=0.31\right)$ and Finnish

$\left(\triangle \mathrm{DIF}_{1.1}=0.65 ; \triangle \mathrm{DIF}_{1.2}=0.10 ; \triangle \mathrm{DIF}_{2.1}=0.06 ; \triangle \mathrm{DIF}_{2.2}=0.23 ; \triangle \mathrm{DIF}_{3.1}=0.07 ; \triangle \mathrm{DIF}_{4.1}=0.32\right)$

data were $<0.5$ logits, with the exception of item 1.1 that measured brainstorming in the

Finnish data. Additionally, differences between the countries in all of the estimates of item

difficulty were $<0.5$ logits. The person separation reliabilities for scientific imagination

were .82 and .78 for the Taiwanese and Finnish students, respectively.

Table 3.

Estimates of item difficulty and goodness-of-fit values for scientific imagination in Taiwanese and Finnish students.

\begin{tabular}{ccccccc}
\hline $\begin{array}{c}\text { Data } \\
\text { resource }\end{array}$ & Item & Step & $\begin{array}{c}\text { Estimates of } \\
\text { item difficulty }\end{array}$ & $S E$ & $\begin{array}{c}\text { OUTFIT } \\
M N S Q\end{array}$ & $\begin{array}{c}I N F I T \\
M N S Q\end{array}$ \\
\hline Taiwan & 1.1 & 0 & & & 1.65 & 1.12 \\
& & 1 & -1.13 & 0.25 & 0.76 & 0.89 \\
& & 2 & -0.09 & 0.26 & 0.88 & 0.95 \\
& & 3 & 1.22 & & 1.44 & 0.98 \\
\hline
\end{tabular}




\begin{tabular}{|c|c|c|c|c|c|c|}
\hline \multirow[t]{19}{*}{$\begin{array}{c}\text { Data } \\
\text { resource }\end{array}$} & \multirow[t]{4}{*}{ Item } & Step & $\begin{array}{l}\text { Estimates of } \\
\text { item difficulty }\end{array}$ & $S E$ & $\begin{array}{l}\text { OUTFIT } \\
\text { MNSQ }\end{array}$ & $\begin{array}{l}\text { INFIT } \\
\text { MNSQ }\end{array}$ \\
\hline & & 1 & -1.71 & 0.27 & 0.89 & 0.93 \\
\hline & & 2 & 0.24 & 0.28 & 0.87 & 0.98 \\
\hline & & 3 & 1.47 & & 0.49 & 0.91 \\
\hline & \multirow[t]{4}{*}{2.1} & 0 & & & 0.77 & 0.88 \\
\hline & & 1 & -1.77 & 0.26 & 0.91 & 0.94 \\
\hline & & 2 & 0.79 & 0.32 & 0.87 & 0.98 \\
\hline & & 3 & 0.98 & & 0.79 & 1.12 \\
\hline & \multirow[t]{4}{*}{2.2} & 0 & & & 0.76 & 0.88 \\
\hline & & 1 & -2.07 & 0.28 & 0.93 & 0.94 \\
\hline & & 2 & 0.38 & 0.31 & 0.85 & 0.95 \\
\hline & & 3 & 1.69 & & 0.63 & 1.10 \\
\hline & \multirow[t]{4}{*}{3.1} & 0 & & & 1.14 & 1.14 \\
\hline & & 1 & -1.13 & 0.27 & 0.96 & 1.01 \\
\hline & & 2 & 0.07 & 0.41 & 1.63 & 1.05 \\
\hline & & 3 & 1.07 & & 4.01 & 1.29 \\
\hline & \multirow[t]{3}{*}{4.1} & 0 & & & 1.07 & 1.12 \\
\hline & & 1 & -0.28 & 0.28 & 0.89 & 0.98 \\
\hline & & 2 & 0.28 & & 2.06 & 1.29 \\
\hline \multirow{24}{*}{ Finland } & \multirow[t]{4}{*}{1.1} & 0 & & & 0.78 & 1.00 \\
\hline & & 1 & -1.55 & 0.26 & 2.13 & 1.23 \\
\hline & & 2 & -0.23 & 0.24 & 1.09 & 1.07 \\
\hline & & 3 & 1.78 & & 1.42 & 1.18 \\
\hline & \multirow[t]{4}{*}{1.2} & 0 & & & 1.67 & 1.19 \\
\hline & & 1 & -1.72 & 0.28 & 1.19 & 1.08 \\
\hline & & 2 & -0.27 & 0.26 & 1.05 & 1.07 \\
\hline & & 3 & 1.99 & & 0.63 & 1.04 \\
\hline & \multirow[t]{4}{*}{2.1} & 0 & & & 0.59 & 0.84 \\
\hline & & 1 & -1.61 & 0.26 & 1.03 & 1.02 \\
\hline & & 2 & 0.32 & 0.27 & 0.92 & 0.98 \\
\hline & & 3 & 1.29 & & 1.26 & 0.99 \\
\hline & \multirow[t]{4}{*}{2.2} & 0 & & & 0.59 & 0.83 \\
\hline & & 1 & -2.38 & 0.30 & 0.93 & 0.94 \\
\hline & & 2 & -0.21 & 0.28 & 0.79 & 0.91 \\
\hline & & 3 & 2.59 & & 0.42 & 0.99 \\
\hline & \multirow[t]{4}{*}{3.1} & 0 & & & 0.66 & 0.80 \\
\hline & & 1 & -2.05 & 0.26 & 0.90 & 0.91 \\
\hline & & 2 & 0.51 & 0.36 & 0.62 & 0.89 \\
\hline & & 3 & 1.54 & & 5.53 & 1.10 \\
\hline & \multirow[t]{4}{*}{4.1} & 0 & & & 0.74 & 0.85 \\
\hline & & 1 & -1.85 & 0.26 & 0.92 & 0.94 \\
\hline & & 2 & -0.41 & 0.33 & 0.72 & 0.92 \\
\hline & & 3 & 2.26 & & 0.17 & 1.02 \\
\hline
\end{tabular}

Interpretability evidence. Figure 1 shows individual performance data and the Thurstone threshold item difficulty for Taiwanese and Finnish students. Each ' $X$ ' to the left of Figure 1 denotes one individual's scientific imagination ability. The digit on the right denotes the item 
number corresponding to the second Thurstone threshold. Positive values indicate higher levels of scientific imagination ability achieved by that individual; the higher the value for an item, the less likely it was that the individual had achieved scientific imagination with regard to that item. The item difficulty values for scientific imagination as measured by the SIT-Verbal $\left(M_{T}=0.24, M_{F}=-0.04 ; S D_{T}=0.73, S D_{F}=1.03\right)$ were higher in the Taiwanese and Finnish students than the scientific imagination scores for $5^{\text {th }}$ and $6^{\text {th }}$ graders $\left(M_{T}=-0.78\right.$, $\left.M_{F}=-0.61 ; S D_{T}=1.09, S D_{F}=0.99\right)$. Overall, the hierarchy of the scientific imagination process was confirmed, with the exception of conceptualisation/organisation/formation. 


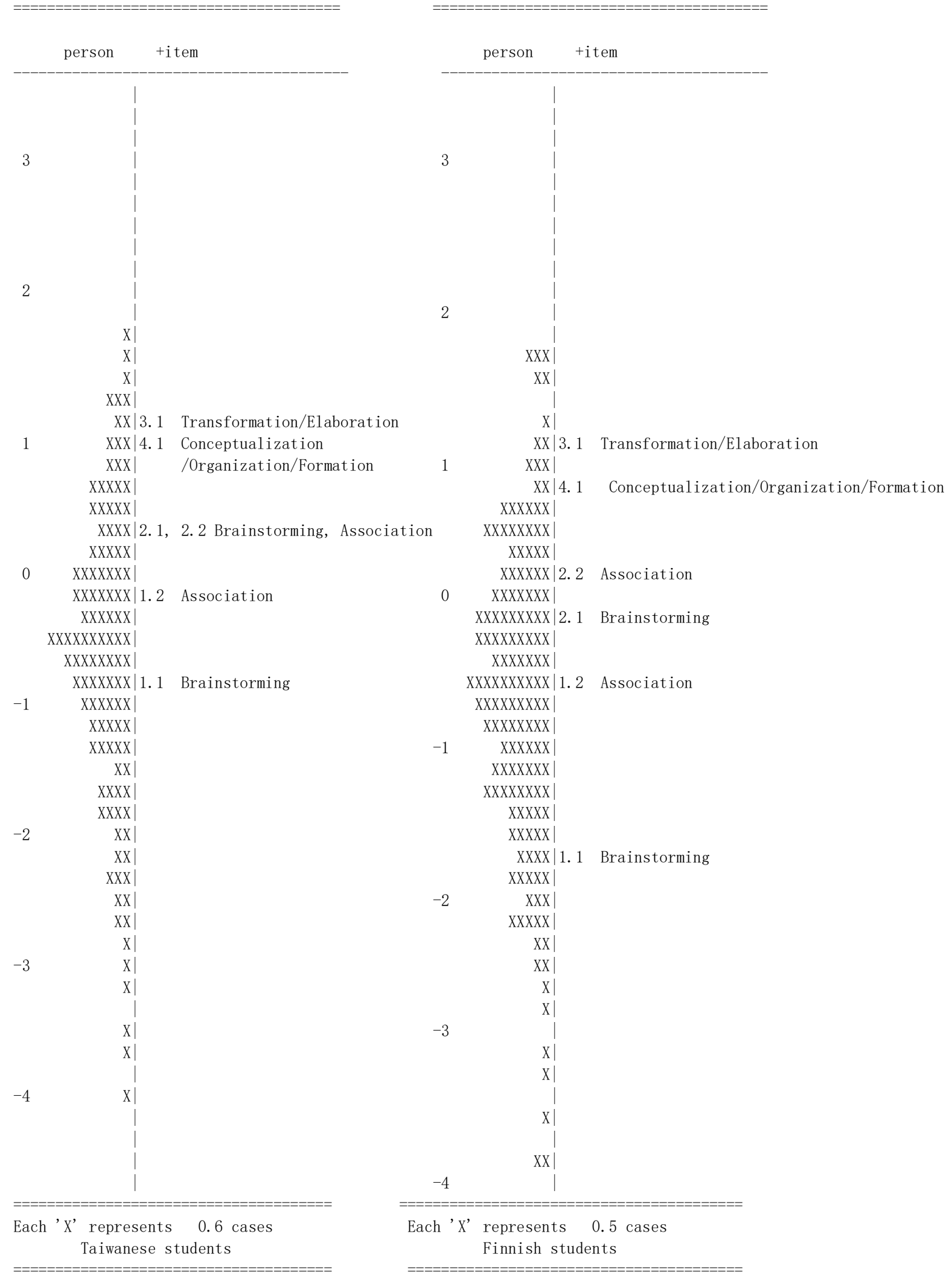

Figure 1. Individual performance data and second Thurstone threshold item difficulty for Taiwanese and Finnish students. 
Table 4 lists the differences in scientific imagination due to gender and grade for the Taiwanese and Finnish samples. Among the Taiwanese students, females $(M=-0.31 ; S D=$ $0.80)$ significantly outperformed males $(M=-1.19 ; S D=1.16)$ on scientific imagination $(t=$ $-3.84, p<.001)$. The results showed no significant difference between $5^{\text {th }}(M=0.42 ; S D=$ $0.88)$ and $6^{\text {th }}$ graders $(M=-0.82, S D=1.09)$, as determined by a $t$-test $(t=1.60, p=.115)$. Among the Finnish students, females $(M=-0.42 ; S D=0.72)$ outperformed males $(M=$ $-0.83 ; S D=1.20)$ on scientific imagination, but the $t$-test results showed that this difference was not significant $(t=-1.73, p=.089)$.

Table 4.

Means and standard deviations for scientific imagination scores according to gender and grade.

\begin{tabular}{|c|c|c|c|}
\hline country & Category $(N)$ & & Scientific imagination \\
\hline \multirow[t]{12}{*}{ Taiwan } & Gender & & \\
\hline & Male $\quad(40)$ & $M$ & -1.19 \\
\hline & & $S D$ & 1.16 \\
\hline & Female (34) & $M$ & -0.31 \\
\hline & & $S D$ & 0.80 \\
\hline & Grade & & \\
\hline & $5^{\text {th }}$ grader $(2)$ & $M$ & 0.42 \\
\hline & & $S D$ & 0.88 \\
\hline & $6^{\text {th }}$ grader $(72)$ & $M$ & -0.82 \\
\hline & & $S D$ & 1.09 \\
\hline & Total (74) & $M$ & -0.79 \\
\hline & & $S D$ & 1.09 \\
\hline \multirow[t]{12}{*}{ Finland } & Gender & & \\
\hline & Male & $M$ & -0.83 \\
\hline & & $S D$ & 1.20 \\
\hline & Female (41) & $M$ & -0.42 \\
\hline & & $S D$ & 0.73 \\
\hline & Grade & & \\
\hline & $5^{\text {th }}$ grader $(18)$ & $M$ & -0.65 \\
\hline & & $S D$ & 1.18 \\
\hline & $6^{\text {th }}$ grader $(58)$ & $M$ & -0.60 \\
\hline & & $S D$ & 0.94 \\
\hline & Total (76) & $M$ & -0.61 \\
\hline & & $S D$ & 0.99 \\
\hline
\end{tabular}

Substantive evidence. Our results showed that the stronger the performance achieved by the students, the greater likelihood of their reaching a higher level. For example, Figure 2 
shows the Rasch PCM results for item 1.1. The $x$-axis denotes students' brainstorming at different category levels (unit: logits); the $y$-axis denotes the probability of each level of category. The four curves plotted in Figure 2 correspond to the four levels of understanding related to the item. Taiwanese students (Finnish students) exhibiting an ability below -1.99 $(-3.14)$ logits in brainstorming were more likely to attain a Level 0 category. Students exhibiting an ability ranging from $-1.99(-3.14)$ to $-0.95(-1.82)$ logits, $-0.95(-1.82)$ to $0.36(0.18)$ logits, and $>0.36(0.18)$ logits were more likely to reach categories corresponding to Levels 1, 2, and 3, respectively. This indicates that the assumption of the level settings for each category was well suited to the actual performance of the students.
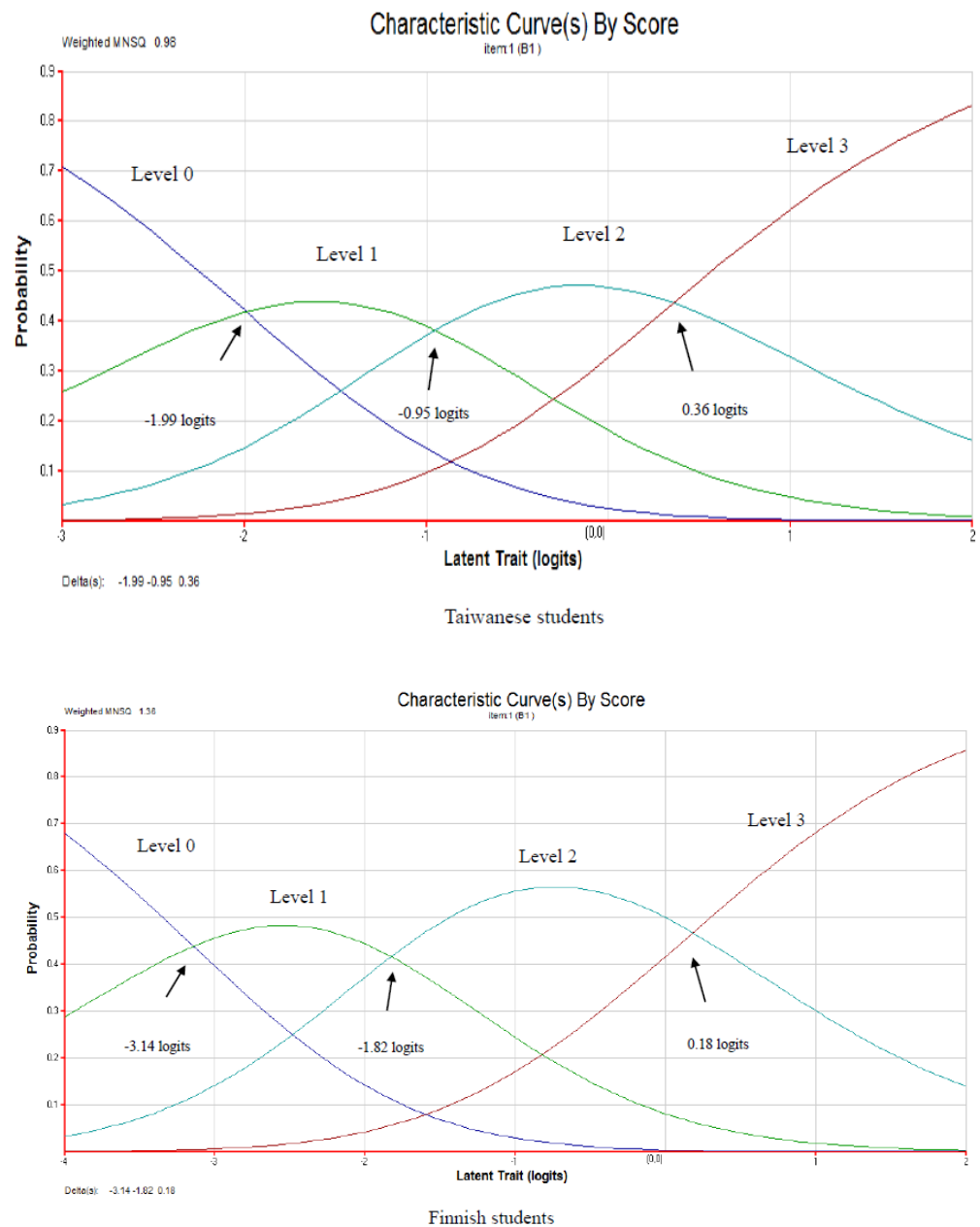

Figure 2. Probabilities of the four category levels of understanding for Taiwanese and Finnish students, using Item 1-1 as an example. 
Differences in scientific imagination between Taiwanese and Finnish students

Overall, the results showed no significant difference between Taiwanese $(M=-0.79 ; S D$ $=1.09)$ and Finnish students $(M=-0.61, S D=0.99)$, as determined by a $t$-test $(t=-1.04, p$ $=.301$, power $=0.30$ ). As shown in Table 5, the category levels achieved by students on the scientific imagination measures were similar for both countries. On item 1.1, most students from both countries reached category 2. On item 1.2, most Taiwanese students reached category 1, but the Finnish students reached category 2. On items 2.1 and 2.2, most students from both countries reached category 1. On item 3.1, most Taiwanese students reached category 0 , but most Finnish students reached category 1. On item 4.1, most Taiwanese and Finnish students reached category 0 . To summarise, the assumption of the level setting for each category was confirmed. In both countries, few students attained high levels of ability. The results also indicated that the Finnish students performed slightly better than the Taiwanese students for some components of scientific imagination. It would be worth investigating the differences in scientific imagination between the two countries further through a large-scale investigation.

Table 5 .

Numbers in boldface indicate the level reached by the largest number of students.

\begin{tabular}{|c|c|c|c|c|c|c|}
\hline \multirow[t]{2}{*}{ Country } & \multicolumn{3}{|c|}{$\begin{array}{l}\text { Taiwan } \\
(N=74)\end{array}$} & \multicolumn{3}{|c|}{$\begin{array}{c}\text { Finland } \\
(N=76)\end{array}$} \\
\hline & $\begin{array}{l}\text { Level of } \\
\text { category }\end{array}$ & Count & PV1Avg:1 & Level & Count & PV1Avg:1 \\
\hline \multirow[t]{4}{*}{1.1} & 0 & 14 & -2.09 & 0 & 4 & -2.76 \\
\hline & 1 & 20 & -1.07 & 1 & 15 & -1.01 \\
\hline & 2 & 24 & -0.18 & 2 & 34 & -0.70 \\
\hline & 3 & 16 & 0.51 & 3 & 23 & -0.07 \\
\hline \multirow[t]{4}{*}{1.2} & 0 & 16 & -1.84 & 0 & 13 & -1.88 \\
\hline & 1 & 30 & -0.71 & 1 & 27 & -0.93 \\
\hline & 2 & 20 & -0.13 & 2 & 29 & -0.21 \\
\hline & 3 & 8 & 0.84 & 3 & 7 & 0.71 \\
\hline \multirow[t]{4}{*}{2.1} & 0 & 18 & -1.74 & 0 & 15 & -2.10 \\
\hline & 1 & 35 & -0.56 & 1 & 31 & -0.71 \\
\hline & 2 & 13 & -0.05 & 2 & 20 & 0.05 \\
\hline & 3 & 8 & 0.61 & 3 & 10 & 0.12 \\
\hline \multirow[t]{3}{*}{2.2} & 0 & 18 & -1.74 & 0 & 15 & -2.10 \\
\hline & 1 & 36 & -0.53 & 1 & 36 & -0.67 \\
\hline & 2 & 16 & 0.04 & 2 & 23 & 0.16 \\
\hline
\end{tabular}




\begin{tabular}{ccccccc} 
& 3 & 4 & 0.75 & 3 & 2 & 0.30 \\
\hline 3.1 & 0 & $\mathbf{4 2}$ & -1.11 & 0 & 26 & -1.78 \\
& 1 & 22 & -0.10 & 1 & $\mathbf{3 8}$ & -0.30 \\
& 2 & 8 & 0.19 & 2 & 10 & 0.55 \\
& 3 & 2 & 0.28 & 3 & 2 & 0.44 \\
\hline 4.1 & 0 & $\mathbf{4 4}$ & -1.10 & 0 & $\mathbf{3 2}$ & -1.55 \\
& 1 & 19 & -0.03 & 1 & 29 & -0.29 \\
& 2 & 11 & 0.21 & 2 & 14 & 0.40 \\
& 3 & 0 & - & 3 & 1 & 1.06 \\
\hline
\end{tabular}

Note, PV1Avg:1 means the average ability of students responding in each category.

\section{Discussion and conclusions}

This exploratory study aimed to examine the validity of LP in scientific imagination of elementary school students in Taiwan and Finland. It also explored differences in scientific imagination due to gender and country of residence. Despite the small sample size, multiple examples of the validity of LP in scientific imagination were effectively presented using the Rasch analysis.

With respect to content and structural validity, the results indicated that all of the items of the Chinese and Finnish versions of the SIT-Verbal had a good model-data fit. With regard to generalisability, no DIF items were found between the countries. However, one gender DIF item (item 1.1 measuring brainstorming: "Question 1: What problems might this situation bring about? ...") was found in the Finnish sample. However, owing to the small sample size, it is difficult to explain the occurrence of such a DIF or to make generalisations. This requires further study using a larger sample size to provide more plausible explanations. In addition, there was considerable person-separation reliability for scientific imagination among the Taiwanese and Finnish students (Bond \& Fox, 2007). With regard to substantive evidence, our results showed that the higher the ability of the students, the greater the probability of them choosing a higher level. This indicated that the assumption of the level setting for each category was well aligned with the actual performance of the students.

With respect to interpretability, the results from both countries showed that the four 
components were hierarchical, with the exception of conceptualisation/organisation/formation. This finding is consistent with results obtained by Wang et al. (2015a, b), indicating that transformation/elaboration was highest among the four components. Transformation/elaboration is defined as evidence that the student can reorganise the physical features and functions of inventions to solve problems, and conceptualisation/organisation/formation refers to the ability of students to refine their previous activities to create a prototype for their specific ideas, including details related to the choice of materials, techniques for assembling parts, and the means to create design diagrams and final drafts based on their initial diagrams (Wang et al., 2015a, b). According to Ren et al. (2012), students express their creativity in different ways at different ages. Younger students prefer to express their thinking through drawings, as this is easier for elementary school students than using language. Moreover, elementary school students' thinking may suggest alignment with scientific principles, but this may be difficult to determine based on their limited cognitive abilities. In other words, the hierarchies of transformation/elaboration and conceptualisation/organisation/formation may be different at elementary school level. Therefore, we suggest further study with additional and more varied samples, including pupils at junior and senior levels or even higher, to provide further evidence for LP related to scientific imagination at different ages.

No significant differences in scientific imagination were found between the countries of residence. With regard to gender, females outperformed males in Taiwan and Finland, but a significant gender difference was found only in Taiwan. However, no significant difference in scientific imagination due to gender was observed in a previous study by Wang et al. (2015a). Previous research on creativity and imagination was inconclusive regarding gender-based differences. To achieve a better understanding of the classroom performance of males and females on tasks related to scientific imagination, further research should be conducted with the focus on providing qualitative data, for example, based on interviews or observations 
pertaining to teacher-student and student-student interactions in instructional settings.

Finally, no significant difference was observed between Taiwanese and Finnish students. However, Finnish students' performance was slightly higher than that of Taiwanese students in some components of scientific imagination. For example, the Finnish students created a greater number of drawings than the Taiwanese students. These results echo the findings of Liou and Lan (2016), who reported that Asian and Western students performed equally well overall on tasks demanding creativity; however, Asian students performed well on practical aspects, whereas Western students showed greater originality. Moreover, students belonging to the same culture created similar products. Ward (1994) proposed that imagination is guided, showing many common features reflecting similarity in structure and process. Hence, it would be fruitful to conduct future research involving large-scale and detailed investigations of differences in scientific imagination between the two countries.

Imagination undergoes various transformations over the course of a person's development (Eckhoff \& Urbach, 2008; Vygotsky, 2004). As a result, the development and verification of LP must be continuously revised throughout the developmental process to accommodate the age of the learner (Shea \& Duncan, 2013; Songer et al., 2009). In this study, we succeeded in validating the scientific imagination process based on the LP of this concept (Wang et al., 2015a, b) using Finnish and Taiwanese data. In other words, the scientific imagination process might be deemed reliable and valid in two culturally different student groups. Additional research is needed in the form of large-scale investigations between the two countries and detailed comparisons using qualitative data to examine the differences in scientific imagination between Finnish and Taiwanese elementary school students. Such research would help future teachers to guide students to conduct scientific projects and participate in scientific contests, and to foster multiple abilities from a number of different perspectives. 


\section{Reference}

Adams, J. (2004). The imagination and social life. Qualitative Sociology, 27, 277-297. doi: 10.1023/B:QUAS.0000037619.28845.ef

Bond, T. \& Fox, C. (2007). Applying the Rasch model: Fundamental measurement in the human sciences (2nd). Mahwah, NJ: LEA.

Church, E. B. (2006). Let's invent. Scholastic Parent \& Child, 13, 28-35.

Cruz, H. D., \& Smedt, J. D. (2010). Science as structured imagination. Journal of Creative Behavior, 44, 29-44. doi: 10.1002/j.2162-6057.2010.tb01324.x

Department of Science Education (2009). 2009-intergrated program of Imagination and technology research/nurture of implementation capacity. Cited from: http://www.nsc.gov.tw/sci/ct.asp?xItem $=16326 \& c t$ Node $=3395$

Eckhoff, A., \& Urbach, J. (2008). Understanding imaginative thinking during childhood: Sociocultural conceptions of creativity and imaginative thought. Early Childhood Educ $J$, 36, 179-185. doi: 10.1007/s10643-008-0261-4

Grant, E. (2004). Scientific imagination in the middle ages. Perspectives on Science, 12, 394-423. doi: 10.1162/1063614042776021

Ho, H. C., Wang, C. C., \& Cheng, Y. Y. (2013). Analysis of the Scientific Imagination Process. Thinking Skills and Creativity, 10, 68-78.

Kim, K. H. (2005). Learning from each other: Creativity in East Asian and American Education. Creativity Research Journal, 17, 337-347.

Lin, W. W. (2011). The Nurture of Imagination and Creation: Arkki, School of Architecture for Children and Youth in Republic of Finland. Elementary Education, 51, 62-72. (In Chinese)

Linacre, J. M. (1998). Thurstone thresholds and the Rasch model. Rasch Measurement Transactions, 12, 634-635.

Liou S. \& Lan X. (2016, forthcoming). Situational Salience of Norms Moderates Cultural Differences in the Originality and Usefulness of Creative Ideas Generated or Selected by Teams. Journal of Cross-cultural Psychology.

Luo, J. X., Olechowski, A. L., \& Magee, C. L. (2014). Technology-based design and sustainable economic growth. Technovation, 11, 663-677. doi:

10.1016/j.technovation.2012.06.005

Masters, G. N. (1982). A Rasch model for partial credit scoring. Psychometrika, 47, 149-174.

Meskanen, P. (2012) 'Encouraging Children and Youth to Participation, Get Involved, International Symposium, Architectural and Built Environment Education for young people. International Architecture Exhibition La Biennale di Venezia' Online. Available http://www.baukulturvermittlung.at/wp/wp-content/plugins/download-monitor/downloa d.php?id=132 (accessed 8 April 2013).

Messick, S. (1994). The interplay of evidence and consequences in the validation of 
performance assessments. Educational Researcher, 23, 13-23. doi:

10.3102/0013189X023002013

Messick, S. (1995a). Standards of validity and the validity of standards in performance assessment. Educational Measurement: Issues and Practice, 14, 5-8. doi:

10.1111/j.1745-3992.1995.tb00881.x

Messick, S. (1995b). Validity of psychological assessment: Validation of inferences from persons' responses and performances as scientific inquiry into score meaning. American Psychologist, 50, 741-749. doi: 10.1037/0003-066X.50.9.741

Ministry of Education Advisory Office (2012). Humanity and Social Science Education Plan. Cited from: http://hss.edu.tw/plan_detail.php?class_plan=174

Mountain, V. (2007). Educational contexts for the development of children's spirituality: Exploring the use of imagination. International Journal of Children's Spirituality, 12, 191-205. doi: 10.1080/13644360701467535

Niemi, H., Multisilta, J., Lipponen, L., \& Vivitsou, V. (Eds.) 2014. Finnish Innovations and Technologies in Schools. Towards New Ecosystems of Learning, Sense Publishers.

Reinikainen, P. (2012). Amazing PISA results in Finnish comprehensive schools. In H. Niemi, \& A. Kallioniemi, \& A. Toom (Eds.), The Miracle of Education: The Principles and Practices of Teaching and Learning In Finnish Schools (pp.3-18). Rotterdam: Sense.

Ren, F., Li, X., Zhang, H., \& Wang, L. (2012). Progression of Chinese students' creative imagination from elementary through high school. International Journal of Science Education, 34, 2043-2059. doi: 10.1080/09500693.2012.709334

Sahlberg, P. (2007). Education policies for raising student learning: The Finnish approach. Journal of Education Policy, 22, 147-171.

Sala-i-Martín, X., Bilbao-Osorio, B., Battista, A. D., Hanouz, M. D., Geiger, T., \& Galvan, C. (2014). The global competitiveness index 2014-2015: Accelerating a robust recovery to create productive jobs and support inclusive growth. Retrieved from http://www3.weforum.org/docs/WEF_GlobalCompetitivenessReport_2014-15.pdf

Schumacker, R. E., \& Smith, E. V., Jr. (2007). Reliability: A Rasch perspective. Educational and Psychological Measurement, 67, 394-409.

Shea, N. A., \& Duncan, R. G. (2013). From theory to data: The process of refining learning progressions. The Journal of the Learning Sciences, 22, 7-32. doi: 10.1080/10508406.2012.691924

Songer, N. B., Kelcey, B., \& Gotwals, A. W. (2009). How and when does complex reasoning occur? Empirically driven development of a learning progression focused on complex reasoning about biodiversity. Journal of Research in Science Teaching, 46, 610-631. doi: 10.1002/tea.20313

Vygotsky, S. L. (1930/2004). Imagination and creativity in childhood. Journal of Russian and East European Psychology, 42, 7-97. 
Wang, C. C., Ho, H. C., \& Cheng, Y. Y. (2015a). Building a learning progression for scientific imagination: A measurement approach. Thinking Skills and Creativity, 17, 1-14. doi: 10.1016/j.tsc.2015.02.001

Wang, C. C., Ho, H. C., \& Cheng, Y. Y. (2015b). Validation of the Scientific Imagination Test-Verbal. Paper will present at the Pacific Rim Objective Measurement Symposium (PROMS) 2015, Fukuoka, Japan

Ward, T. B. (1994). Structured imagination: The role of category structure in exemplar generation. Cognitive Psychology, 27, 1-40.doi:10.1006/cogp.1994.1010

Wilson, M. (2005). Constructing measures: An item response modeling approach. Mahwah, NJ: Erlbaum.

Wilson, M. (2009). Measuring processions: Assessment structures underlying a learning progression. Journal of Research in Science Teaching, 46, 716-730. doi: $10.1002 /$ tea. 20318

Wolfe, E. W., \& Smith, E. V., Jr. (2007). Instrument development tools and activities for measure validation using Rasch models: Part II-Validation activities. Journal of Applied Measurement, 8, 204-233.

Wu, J. J. (2002). Enticing the crouching tiger and awakening the hidden dragon: Recognizing and nurturing creativity in Chinese students. Research in Applied Psychology, 15, 17-42. (in Chinese)

Wu, M. L., Adams, R. J., \& Wilson, M. R. (2007). ConQuest [Computer software and manual]. Camberwell, Victoria, Australia: Australian Council for Educational Research. 
Appendix A: Scientific imagination and its indicators

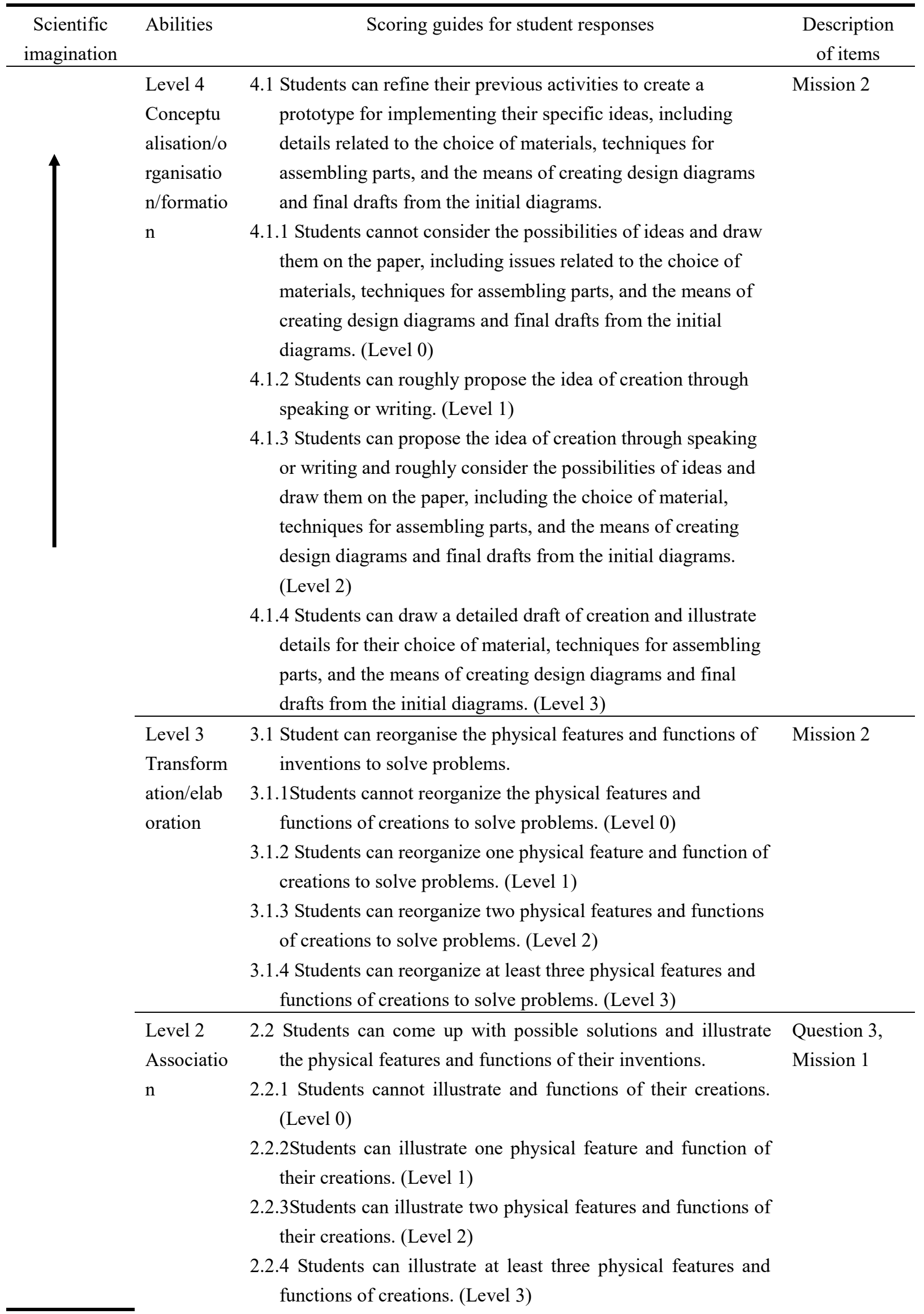


2.1 Students can specify problems relating to their life experience.

2.1.1 Students cannot specify problems correlate with life

Question 2, experience. (Level 0)

Mission 1

2.1.2 Students can specify one problem correlate with life experience. (Level 1)

2.1.3 Students can specify two problems correlate with life experience. (Level 2)

2.1.4 Students can specify at least three problems correlate with life experience. (Level 3)

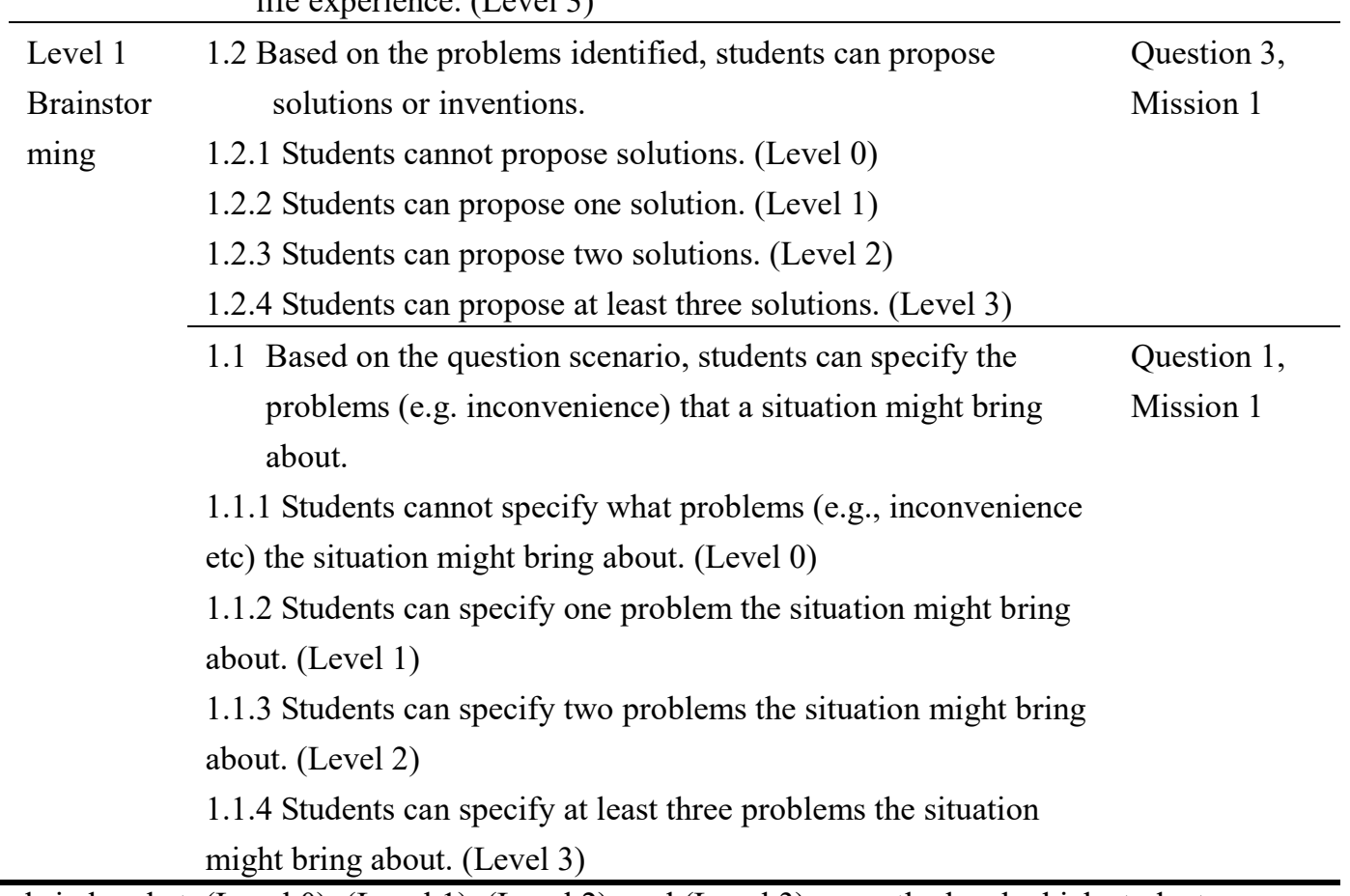

Note1. The words in bracket, (Level 0), (Level 1), (Level 2), and (Level 3) mean the level which students can reach in this stage. Taking indicator 1.1 as an example, the lowest performance (Level 0 ) is students cannot propose what problems (e.g., inconvenience) the situation might bring about for students' brainstorming in initiation stage; the highest performance (Level 3) is students can specify at least three problems the situation might bring about.

Note2. From "Validation of the Scientific Imagination Test-Verbal", by C. C. Wang, H. C. Ho, \& Y. Y. Cheng. 2015, Paper presented at the Pacific Rim Objective Measurement Symposium (PROMS) 2015, Fukuoka, Japan. 